\title{
DIRECT CARBON FUEL CELL SIMULATION USING HYBRID LB-FV APPROACH: EFFECT OF CARBON FUEL MICROSTRUCTURE
}

\author{
A. EL MANSOURI, M. HASNAOUI*, I. FILAHI, A. AMAHMID, M. ALOUAH and Y. \\ DAHANI
}

\author{
UCA, Faculty of Sciences Semlalia, Physics Department, LMFE, BP 2390, Marrakesh, Morocco \\ *Corresponding author: hasnaoui@uca.ac.ma
}

\begin{abstract}
In the present study, the simulation of the direct carbon fuel cell (DCFC) using a hybrid Lattice Boltzmann and finite volume approach is performed. The numerical model was first validated against available experimental data. Parametric studies were carried out to investigate the effect of the microstructure of the carbon fuel on the DCFC performance. The increase of the specific surface area (SSA) or porosity was found to minimize the voltage drop in the cell and ameliorate its output power density. In contrary, the increase of the tortuosity was found to inversely affect these results.
\end{abstract}

Keywords: Direct carbon fuel cell, Lattice Boltzmann method, Carbon fuel, Specific surface area, Porosity, Tortuosity.

\section{Introduction}

Fuel cells are small-scale reactors that allow the conversion of various types of fuels into electric power, which is a high-quality energy [1]. Direct Carbon Fuel Cells (DCFCs) have the privilege of directly using solid carbon as fuel, which reduces the pretreatment process steps. The main steps circumvented by using DCFCs are gasification and filtration processes required in the conversion of biomass into fuel gas before supplying the latter to the other types of fuel cells. The DCFC technology is expected to contribute to an increase of the waste recycling capacity, which represents nowadays an increasing challenge of concern to humanity.

The use of high specific surface area (SSA) material in the electrodes (biochar for the anode), contributes to increase the current density and thereby reduces the cell surface area required to reach a given current $\left(I=i \times S_{\text {cell }}\right)$ and the size of the fuel cell. In fact, in many applications the size, the volume, the energy density and the power density are more important than efficiency [2]. Many compact designs were reported in the literature. The most used ones are the planar and tubular designs sketched in figure 1 for the DCFC case [3]. The planar design is characterized by its simplicity, easy stacking and high energy density (characteristics required in mobile applications). However, the planar design is the object of mechanical instability problems. The tubular design has the advantage to offer higher energy efficiencies even if it suffers from high ohmic losses and low energy densities.

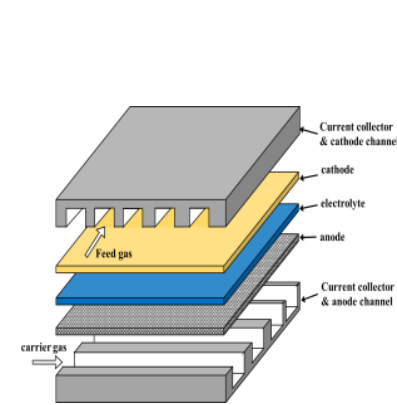

(a)

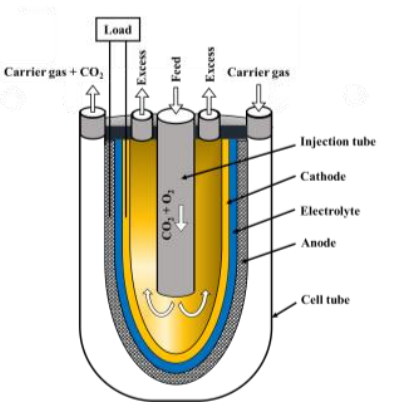

(b)
Figure 1. Schematic of the planar (a) and Tubular (b) fuel cell designs.

The potential of the fuel cell at the equilibrium is giving by the Nernst equation as follows:

$\mathrm{E}=\mathrm{E}^{\circ}+(\mathrm{RT} / \mathrm{nF}) \log \left(\mathrm{X}_{\mathrm{CO} 2} / \mathrm{X}_{\mathrm{O} 2}\right)$

where $\mathrm{E}^{\circ}=-\Delta \mathrm{G}^{\circ} / \mathrm{nF}$ and $\mathrm{E}$ are the standard potential and the open circuit voltage (OCV) of the DCFC, respectively. The parameters $\mathrm{X}_{\mathrm{CO} 2}$ and $\mathrm{X}_{\mathrm{O} 2}$ are the partial pressures of used gazes. In the presence of electrical current in the DCFC, the cell voltage may drop due to the activation, ohmic and concentration losses. The activation losses $\left(\eta_{\text {act }}\right)$ represent the energy spent to allow the charges crossing the potential barrier at the electrolyte-electrode boundaries. The ohmic losses $\left(\eta_{\mathrm{ohm}}\right)$, are caused by the resistance of the different components of the fuel cell to the electric current passage. The concentration losses $\left(\eta_{\text {conc }}\right)$, are related to the concentrations of reactant and product gases at the reaction sites. Therefore, the voltage of the DCFC can be written as follows:

$\mathrm{V}=\mathrm{E}-\left(\eta_{\text {act }}+\eta_{\text {conc }}\right)_{\text {anode }}-\eta_{\text {ohm,cell }}-\left(\eta_{\text {act }}+\eta_{\text {conc }}\right)_{\text {cathode }}(2)$

The performance of the DCFC can be enhanced by reducing the polarization losses associated to different transport processes in the fuel cell.

In the present work, dedicated to the anodic polarization (in particular the activation and concentration losses), we model and simulate the DCFC using the Lattice Boltzmann method. Unlike the experimental tests that are limited by economic and time costs, the DCFC 
simulations will allow multiplicity of tests with very low costs and in reduced times. The developed numerical tool is expected to facilitate the optimization of the DCFC performance through a detailed parametric study of the controlling parameters. A particular emphasis is placed on the anode parameters, particularly those of the carbon fuel.

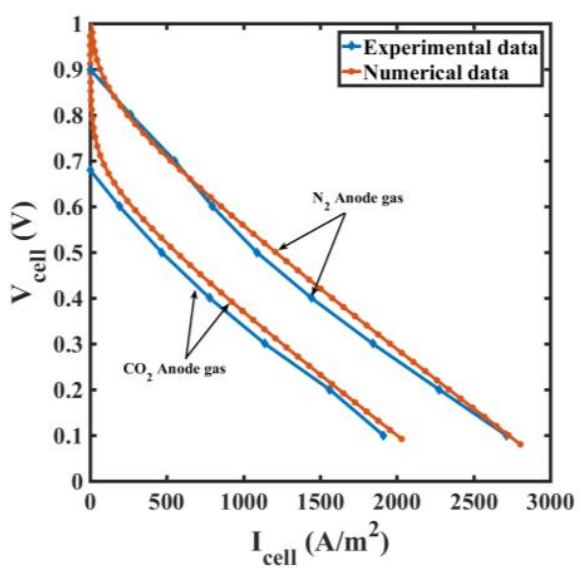

Figure 2. I-V curves of the DCFC (comparison with the data from ref. [5]).

\section{Numerical method}

The mathematical model used to simulate the transient behavior of the direct carbon fuel cell is based on:

- The Navier-Stockes equations that describe the mass and momentum conservations.

- The conservation equations of all species present in the cell $\left(\mathrm{O}_{2}, \mathrm{CO}_{2}, \mathrm{~N}_{2}\right)$.

- The ionic and electronic charge conservation equations.

- The Butler-Volmer equation for the estimation of the reaction rates.

The DCFC is assumed to operate under a fixed temperature. The fluid flows were solved using the Lattice-Boltzmann method with the Cascaded MultiRelaxation Time scheme (CMRT) [4]. The species conservation equations were solved using the finite volume discretization approach.

Results obtained with the present model are validated against available experimental data from the literature [5]. The polarization curve is calculated in two cases; with anode purging $\left(\mathrm{N}_{2}\right.$ anode gas) and without purging $\left(\mathrm{CO}_{2}\right.$ anode gas). Fig. 2 shows that the experimental data are faithfully reproduced and the agreement is very satisfactory.

\section{Results and discussion}

The activation losses are mainly related to the kinetics of the reactions at the electrodes. Meanwhile, the concentration losses depend on the availability of the reactants and abundance of the products near the reaction sites (Triple Phase Boundaries, TPBs). In the following, we examine the effect of the microstructure parameters on these losses.

\subsection{Effect of the specific surface area}

The oxidation rate is strongly dependent on the specific surface area, which is constituted by the TPBs (coexistence of solid carbon, molten carbonate and gas phase) at the anode side. Fig. 3 shows that the activation losses are considerably reduced by the increase of the specific surface area (SSA). As a consequence, the cell voltage and electric power generated between the electrodes are improved. Below $250 \mathrm{~A} / \mathrm{m}$, the gain accompanying the increase of the SSA is variable with the current density while it remains practically constant above this value.

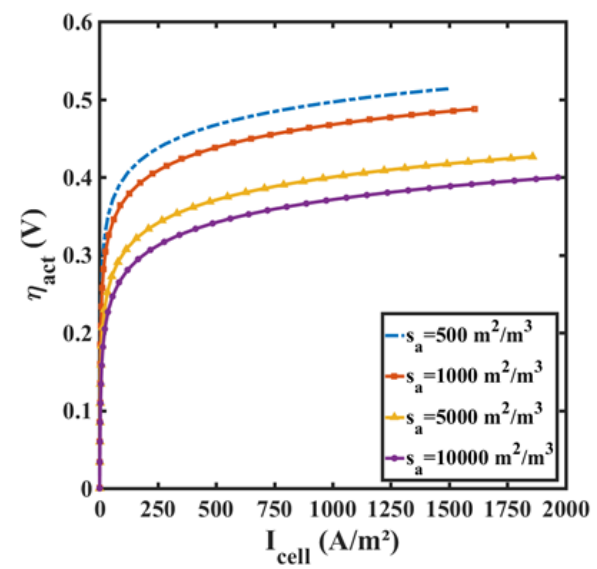

Figure 3. Anode activation losses vs. current density for different values of the surface area.

\subsection{Effect of the porosity and permeability}

The low permeability inhibits the convective motion in the porous anode and it is limited to the feed channels as shown in figure 4 . The figure shows also the distribution of the $\mathrm{CO}_{2}$ concentration in the cell at $\mathrm{V}=0.4$ volts corresponding to the maximum power output. This distribution is not uniform due to gas consumption in the cathode side and production in the anode side. The impact of such a change in the concentration of $\mathrm{CO}_{2}$ reduces the cell voltage by increasing the concentration losses.

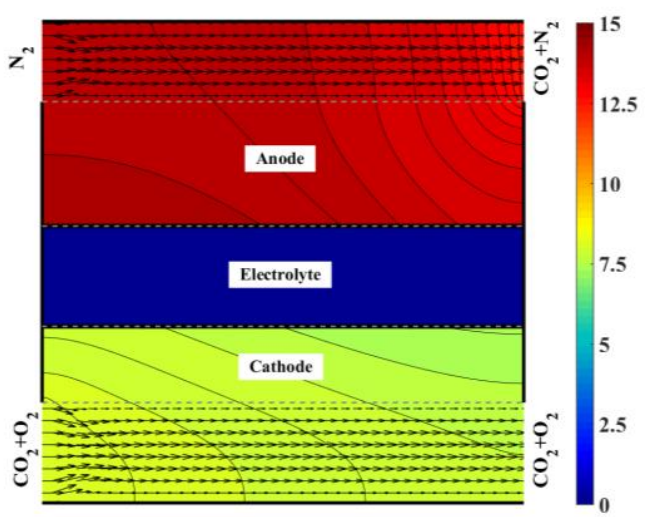

Figure 4. Velocity filed (arrows) and $\mathrm{CO}_{2}$ concentration field (contours and colors) in the DCFC.

The effect of the anode porosity on the anodic concentration losses is plotted in figure 5 for a moderate tortuosity $(\tau=6.08)$. The concentration losses are reduced by the increase of the anode porosity simply because the mass transfer is enhanced. Note that the 
porosity affects negatively the electric conductivity of the anode and its effect is neglected here.

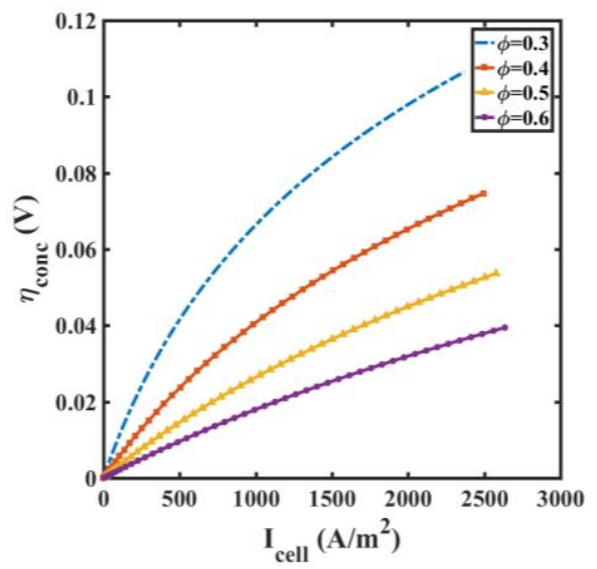

Figure 5. Anode porosity effect on the concentration losses

\subsection{Effect of the tortuosity}

The effect of the tortuosity $\tau$ on the concentration losses is presented in figure 6 (its effect on the anode electrical conductivity is not considered here) for a porosity $\phi=$ 0.3 . The commonly used formula expresses the tortuosity as a function of porosity as follows:

$\tau=\phi^{-p}$

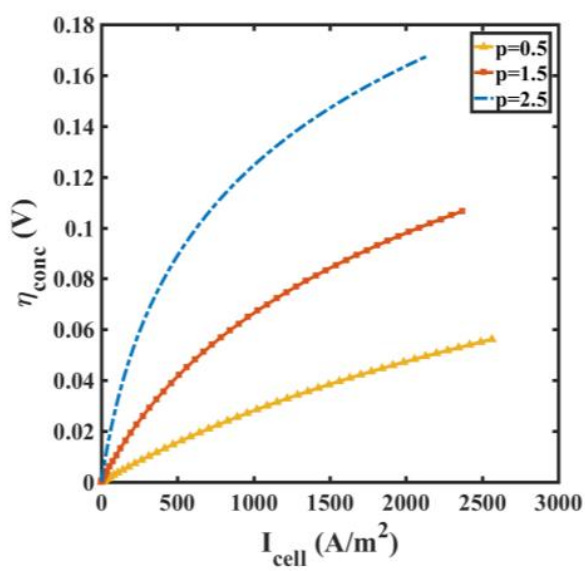

Figure 6. Anode tortuosity effect on the concentration losses.

The value $\mathrm{p}=0.5$ is used for an anode material manufactured from the superposition of several planes of spherical carbon particles. This structure offers the lowest concentrations as it makes easier the evacuation of $\mathrm{CO}_{2}$ from the anode. Fig. 6 shows that the concentration losses become obviously more important for tortuous anode structures $(\mathrm{p}=1.5$ and $\mathrm{p}=2.5)$.

\section{Conclusion}

The developed two-dimensional numerical model allows to describe, in a more realistic way, the gas transport mechanisms and leads to relatively accurate estimation of the concentration polarizations. The parametric study has shown a strong dependency of the cell's polarization losses on the anode microstructure properties. However, most of these properties may have both positive and negative effects on the performance of the DCFC (example: high porosity reduces the concentration losses but rises the ohmic losses). The present model is expected to determine the optimal properties of the biochar for each given DCFC configuration.

\section{Acknowledgment}

The authors would like to gratefully acknowledge the funds received from the Moroccan government in the frame of the ERANETMED program.

\section{References}

[1] C. Chen, J. R. Selman, Anode modeling of a molten-carbonate based direct carbon fuel cell, Journal of power Sources (2017) 353:212-22.

[2] S. Abdullah, S.K. Kamarudin, U.A. Hasran, M.S. Masdar, W.R.W. Daud, Modeling and simulation of a direct ethanol fuel cell: An overview, Journal of Power Sources (2014) 262:401-6.

[3] S. A. Hajimolana, M. A. Hussain, W. M. Daud, M. Soroush, A. Shamiri, Mathematical modeling of solid oxide fuel cells: A review, Renewable and Sustainable Energy Reviews (2011) 15 (4): 1893-1917.

[4] A. El Mansouri, M. Hasnaoui, A. Amahmid, R. Bennacer, Transient modeling of a salt gradient solar pond using a hybrid FiniteVolume and Cascaded Lattice-Boltzmann method: Thermal characteristics and stability analysis, Energy Conversion and Management (2018) 158:416429.

[5] A. Elleuch, J. Yu, A. Boussetta, K. Halouani, Y. $\mathrm{Li}$, Electrochemical Oxidation of Graphite in an Intermediate Temperature Direct Carbon Fuel Cell Based on Two-Phases Electrolyte, International Journal of Hydrogen Energy (2013) 38(20): 8514-23. 